\title{
Implicit and explicit attitudes toward highfat foods in obesity.
}

Citation for published version (APA):

Roefs, A. J., \& Jansen, A. T. M. (2002). Implicit and explicit attitudes toward highfat foods in obesity. Journal of Abnormal Psychology, 111(3), 517-521. https://doi.org/10.1037/0021-843X.111.3.517

Document status and date:

Published: 01/01/2002

DOI:

10.1037/0021-843X.111.3.517

Document Version:

Publisher's PDF, also known as Version of record

Document license:

Taverne

Please check the document version of this publication:

- A submitted manuscript is the version of the article upon submission and before peer-review. There can be important differences between the submitted version and the official published version of record.

People interested in the research are advised to contact the author for the final version of the publication, or visit the DOI to the publisher's website.

- The final author version and the galley proof are versions of the publication after peer review.

- The final published version features the final layout of the paper including the volume, issue and page numbers.

Link to publication

\footnotetext{
General rights rights.

- You may freely distribute the URL identifying the publication in the public portal. please follow below link for the End User Agreement:

www.umlib.nl/taverne-license

Take down policy

If you believe that this document breaches copyright please contact us at:

repository@maastrichtuniversity.nl

providing details and we will investigate your claim.
}

Copyright and moral rights for the publications made accessible in the public portal are retained by the authors and/or other copyright owners and it is a condition of accessing publications that users recognise and abide by the legal requirements associated with these

- Users may download and print one copy of any publication from the public portal for the purpose of private study or research.

- You may not further distribute the material or use it for any profit-making activity or commercial gain

If the publication is distributed under the terms of Article $25 \mathrm{fa}$ of the Dutch Copyright Act, indicated by the "Taverne" license above, 


\title{
Implicit and Explicit Attitudes Toward High-Fat Foods in Obesity
}

\author{
Anne Roefs and Anita Jansen \\ Maastricht University
}

\begin{abstract}
This study examined implicit and explicit attitudes toward high-fat foods in obese $(n=30)$ and normal-weight controls $(n=31)$. The Implicit Association Test (A. G. Greenwald, D. E. McGee, \& J. L. K. Schwartz, 1998) was used to measure the differential association of the 2 target categorieshigh-fat vs. low-fat food words - with an attribute dimension (positive vs. negative). Results suggest that obese people are characterized by a significantly stronger implicit negative attitude toward high-fat foods than are normal-weight controls. This implicit negative attitude is contradictory to their preferences and behavior: Several studies indicate that obese people prefer and consume high-fat foods. Apparently, obese people like the taste of high-fat foods but not the fat content itself, not only on the explicit but also on the implicit level.
\end{abstract}

One of the main questions in obesity research is how people become obese. Various food studies have shown that obesity is more strongly related to the percentage of fat in a diet than to total energetic intake: Obese people's diets contain considerably more fat than the diets of normal-weight people (e.g., Capaldi, 1996; Drewnowski, 1996). The higher fat intake of obese people may be related to their larger preference for high-fat foods: Several studies found that obese people's preference for foods was determined more by fat content than by carbohydrate or sucrose content. Moreover, they showed a larger preference for high-fat foods than did normal-weight controls (e.g., Capaldi, 1996; Drewnowski, 1991; Drewnowski, Brunzell, Sande, Iverius, \& Greenwood, 1985; Drewnowski \& Greenwood, 1983; Drewnowski, Kurth, HoldenWiltse, \& Saari, 1992; Reed, Bachmanov, Beauchamp, Tordoff, \& Price, 1997).

Taste preferences might be considered evaluative categorizations. Evaluative categorizations such as positive-negative can be fast, preconscious, and automatic (e.g., Fazio, Sanbonmatsu, Powell, \& Kardes, 1986; Hermans \& Eelen, 1997). Taste preferences can be seen, therefore, as a special kind of automatic evaluative categorization, that is, in terms of palatable and unpalatable. Conceptualizing taste preferences as automatic evaluative categorizations leads to the prediction that the obese will not only show an explicit behavioral response to high-fat foods but also a fast, preconscious, and automatic preference for these foods.

In this study, we examined the role of preconscious affective processes in the preference for high-fat foods. In particular, we tested whether obese people show a larger preconscious, auto-

Anne Roefs and Anita Jansen, Department of Experimental Psychology, Maastricht University, Maastricht, the Netherlands.

This study is part of an ongoing project and is financed by National Research Organization (NWO) Grant 425-20-801, awarded to Anita Jansen. We thank Fren Smulders for programming the Implicit Association Test paradigm and Gerard van Breukelen, Fren Smulders, and Reinout Wiers for their advice on the statistical analysis.

Correspondence concerning this article should be addressed to Anne Roefs, Department of Experimental Psychology (FdP-UNS 40), Maastricht University, P.O. Box 616, 6200 MD, Maastricht, the Netherlands. E-mail: a.roefs@psychology.unimaas.nl matic, positive response when presented with high-fat food words than do normal-weight controls. If obese participants show an implicit preference for high-fat foods, their preference for high-fat foods might not be changed easily.

\section{Method}

\section{Participants}

The obese group consisted of 24 women and 6 men (age: $M=46.3$ years, $S D=14.8$; weight: $M=93.6 \mathrm{~kg}, S D=13.7$; $\mathrm{BMI}^{1}: M=33.2$ $\mathrm{kg} / \mathrm{m}^{2}, S D=4.6$, range $=27.5-46.2$ ). The normal-weight control group consisted of 25 women and 6 men (age: $M=40.5, S D=14.4$; weight: $M=62.0 \mathrm{~kg}, S D=6.6$; BMI: $M=21.7 \mathrm{~kg} / \mathrm{m}^{2}, S D=1.4$ ). Participants were recruited by press advertisements, asking for overweight and normalweight people, and were selected from the Maastricht population. The two groups did not differ significantly in age, $t(59)=1.58, p=.12$. Medical conditions were checked in an interview, but none of the participants had to be excluded from the study on the basis of this interview. Data from two extra participants were excluded from analysis because of a high error rate $(>20 \%)$.

\section{Overview of the Implicit Association Test (IAT)}

In the current study, the IAT was used to test the hypothesis that obese people have a positive implicit attitude toward high-fat foods. The following description of the IAT procedure focuses on the key aspects of this task (for a more detailed description, see Greenwald, McGhee, and Schwartz, 1998). In the IAT, participants' task was to categorize the presented stimuli (one at a time) as fast and as accurately as possible, according to a concept or an attribute dimension, by pressing the corresponding key (left or right key). Key assignment was counterbalanced over participants. In the first step, high-fat and low-fat food words (concept dimension) were presented (e.g., left $=$ high-fat, right $=$ low-fat). In the second step, positive and negative words (attribute dimension) were presented (e.g., left = positive, right $=$ negative $)$. In the third step, high-fat and low-fat food words and positive and negative words were presented alternately and randomly on the different trials (e.g., left $=$ high-fat/positive, right $=$ low-fat/negative) . In the fourth step, the key assignment for the concept dimension was reversed (e.g., left $=l o w$-fat, right $=$ high-fat). The fifth step was basically

\footnotetext{
${ }^{1} \mathrm{BMI}$ is body mass index: weight/height $\left(\mathrm{kg} / \mathrm{m}^{2}\right)$.
} 
Table 1

Scores on the Explicit Attitudes and Habits Questionnaire Concerning High-Fat Foods

\begin{tabular}{llllll}
\hline & \multicolumn{2}{c}{ Mean score } & & \multicolumn{2}{c}{ Standard deviation } \\
\cline { 2 - 3 } \multicolumn{1}{c}{ Attitudes and habits } & Obese & Control & & Obese & Control \\
\hline 1. High-fat foods taste good & 3.45 & 3.87 & & 1.55 & 1.93 \\
2. High-fat foods are healthy & 5.83 & 5.71 & & 1.71 & 1.68 \\
3. I should not eat high-fat foods & 2.83 & 4.10 & & 1.90 & 1.56 \\
4. In my family, we are careful with high-fat foods & 2.50 & 2.48 & & 1.53 & 1.61 \\
5. I eat a lot of high-fat foods & 4.28 & 5.03 & & 1.85 & 1.77 \\
\hline
\end{tabular}

Note. Scale endpoints are 1 (totally agree) an $\mathrm{d} 7$ (totally disagree).

the same as the third step, but now the key assignment for concepts was reversed (e.g., left $=$ low-fat/positive, right $=$ high-fat/negative). The speed of the responses in Steps 3 and 5 is dependent on the strength of the association between target and attribute assigned to the same key (e.g., high-fat and positive).

If obese people have an implicit preference for high-fat foods, then it should be easier to respond to both high-fat food words and positive words with the same key. It should be more difficult when this combination is reversed, that is, if they have to respond with the same key to both low-fat food words and positive words.

\section{Stimuli of the IAT}

In this study, four sets of 6 stimuli were used: 6 high-fat food words (mean percentage of fat: $31.8, S D=17.7$ ), 6 low-fat food words (mean percentage of fat: $1.4, S D=2.0$ ), 6 positive words, and 6 negative words. Positive and negative words were selected according to norms by Hermans and de Houwer (1994; see Appendix). (Details about timing and stimuli selection closely followed Greenwald et al., 1998, and are available on request.) Stimuli were selected randomly and without replacement from each set (unique for each participant). The set from which a stimulus was selected was also determined randomly (unique for each participant in Steps 1, 2, and 4; fixed sequence per block in Steps 3 and 5). Steps 1, 2, and 4 consisted of 48 experimental trials; Steps 3 and 5 consisted of 96 experimental trials.

\section{Explicit Measures}

In a second task, the same 12 food words as in the IAT were presented in an explicit preference measure to determine whether implicit and explicit measures diverged. Participants judged palatability on a 9-point scale, which varied from -4 (very unpalatable) to 4 (very palatable). In a third task, statements about different attitudes and habits concerning the fat content of foods were presented. We developed this questionnaire to examine taste and health aspects of high-fat foods (Drewnowski, 1991). See Table 1 for the questionnaire items. Participants judged these items on a scale from 1 (totally agree) to 7 (totally disagree).

The Eating Disorder Examination-Questionnaire (EDE-Q; Fairburn \& Beglin, 1994) was used to measure the presence and severity of specific eating psychopathology. This questionnaire measures restraint, eating concern, shape concern, and weight concern. The control group only included people with EDE-Q scores not indicative of eating psychopathology according to norms by Wilson and Smith (1989). The final task for the participants was the completion of the Social Desirability Scale (SDS; Crowne \& Marlow, 1964). The SDS measures the tendency to answer questions in a socially desirable way. This questionnaire was used as a control for the explicit measures.

\section{Procedure}

The IAT was explained to participants as a categorization task in which they had to decide as quickly as possible to which category each stimulus belonged. To reduce possible demand characteristics, no further information was given about the purpose of the study. To motivate participants, the experimenter was present in the test room during the IAT. After taking the IAT, participants completed several explicit measures, were interviewed about their medical and dieting history, and their height and weight were measured. Anne Roefs did all of the testing.

\section{Design}

The IAT data were analyzed in a $2 \times 2 \times 2 \times 2$ analysis of covariance (ANCOVA). Combination (high-fat/positive vs. high-fat/negative) and Order (high-fat/positive followed by high-fat/negative vs. high-fat/negative followed by high-fat/positive) were the two within-subjects variables. The two between-subjects variables were Group (obese vs. control) and Part (1 vs. 2). In Part 1, the participant completed the 5 steps (see Overview of the IAT) for the first time; in Part 2, the participant passed through 4 of the 5 steps again, in the following order: 4-5-1-3. All of these procedural variables were counterbalanced over participants. Following Greenwald et al. (1998), key assignment was not included in the design but was counterbalanced over participants. To control for the wide spread in age in our participants, we included the difference score age minus mean age as a covariate.

\section{Results}

Prior to analysis, following Greenwald et al. (1998), very short responses $(<300 \mathrm{~ms}$ ) were recoded to $300 \mathrm{~ms}$, and very long responses $(>3,000 \mathrm{~ms}$ ) were recoded to $3,000 \mathrm{~ms}$. Moreover, analyses were conducted only on correct responses (94.1\% of the data). After recoding, response latencies were log transformed to stabilize variance and to diminish the influence of outliers. ${ }^{2}$ All reported means were adjusted for the covariate of age.

\section{IAT Effect}

Figure 1 shows the mean response latencies for the two combination steps (3 and 5). As is apparent from this figure, our results were exactly the opposite of our hypothesis. Both obese and normal-weight controls showed evidence of an implicit negative attitude toward high-fat foods in the IAT paradigm. This main effect of combination was significant in an ANCOVA, $F(1,56)=$ 178.28, $M S E=0.028, p<.001, \eta^{2}=.76$. It was easier for them to respond with the same key to the combination of high-fat food words and negative words: obese, mean RT $=775 \mathrm{~ms}$ $(S E M=30.4)$; normal weight, mean $\mathrm{RT}=780 \mathrm{~ms}(S E M=29.9)$,

\footnotetext{
${ }^{2}$ Analyses were also performed on the raw data, but they did not lead to substantially different results or conclusions.
} 


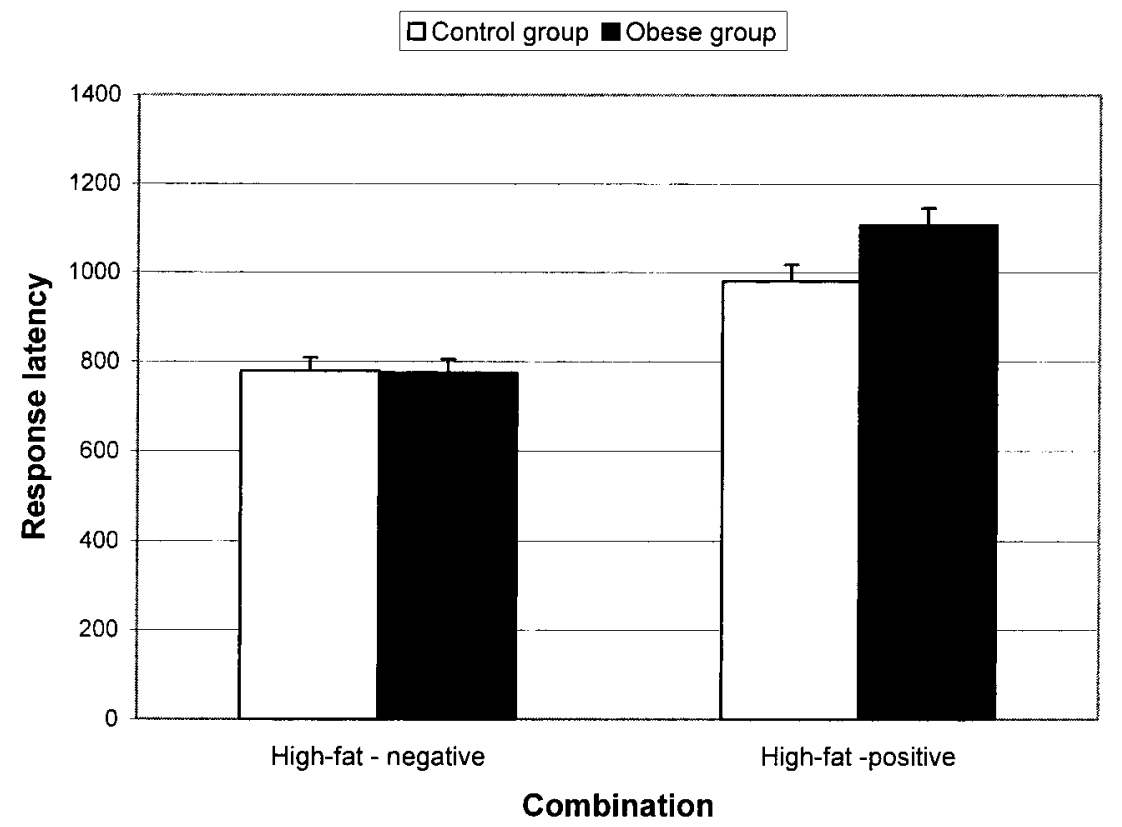

Figure 1. Mean response latencies (in milliseconds), measured with the Implicit Association Test (IAT). They have been adjusted for covariate age and collapsed over order and part. Error bars represent standard errors of measurement.

as opposed to the combination of high-fat food words and positive words: obese, mean RT = 1,107 ms (SEM = 38.0); normal weight, mean $\mathrm{RT}=980 \mathrm{~ms}(S E M=37.4)$.

The main effect was qualified by a Combination $\times$ Group interaction, $F(1,56)=7.89, p<.01, \eta^{2}=.12$. This interaction effect was further explored in two separate ANCOVAs for the combination high-fat/negative and the combination high-fat/positive. For the combination high-fat/negative, the obese group did not differ significantly from the control group $(F<1)$. However, as Figure 1 suggests, obese people responded more slowly to the high-fat/positive combination than did controls, $F(1,56)=5.20$, MSE $=0.076, p<.05, \eta^{2}=.09$.

The covariate of age had a significant main effect, $F(1$, 56) $=22.26, M S E=0.117, p<.001, \eta^{2}=.28$, meaning that older people tended to respond more slowly. There was also a trend toward an Age $\times$ Combination interaction, $F(1,56)=3.35$, $p=.07, \eta^{2}=.06$. Closer examination of the results revealed that age affected response latencies more in the combination high-fat/ positive than in the combination high-fat/negative. This interaction effect could be a consequence of the fact that older people are less capable of suppressing irrelevant information, which in this case was their actual implicit attitude toward high-fat foods (Hasher \& Zacks, 1988).

Different procedural variables had significant effects. First, participants were slower when the combination high-fat/negative preceded the combination high-fat/positive $(M=927 \mathrm{~ms}$, $S E M=21.4)$ as compared with the reversed order $(M=894 \mathrm{~ms}$, $S E M=22.7), F(1,56)=7.64, M S E=0.006, \mathrm{p}<.01, \eta^{2}=.12$. Moreover, there was a significant Combination $\times$ Order interaction. The effect of combination (the IAT effect) was larger when the combination high-fat/negative ( $\mathrm{HF}-$ ) preceded the combination high-fat/positive $(\mathrm{HF}+)$ : $\mathrm{HF}+M=1,101(S E M=29.5)$ vs.
HF- $M=753$ (SEM = 19.3), as compared with the reversed order: $\mathrm{HF}+M=986(S E M=27.0)$ vs. $\mathrm{HF}-M=802$ $(S E M=24.0), F(1,56)=61.35, M S E=0.007, p<.001, \eta^{2}=$ .52. Such procedural effects are common in IAT studies (Greenwald et al., 1998).

\section{Explicit Measures}

On the explicit reference test (scale range $=-4$ to 4 ), participants indicated that they preferred low-fat foods $(M=1.5$, $S D=0.88)$ to high-fat foods $(M=1.1, S D=1.3)$. This main effect of fat content was significant in a 2 (Fat Content: high-fat vs. low-fat) $\times 2$ (Group: obese vs. control) ANOVA, $F(1,59)=5.53$, $M S E=0.929, p<.05, \eta^{2}=.09$. The main effect of group was not significant, $F(1,59)=1.33, M S E=1.55, p>.25$, nor was the interaction effect $(F<1)$.

Table 1 contains the mean scores on the questionnaire about explicit attitudes and habits concerning high-fat foods. Obese people and controls differed only in their scores on the third statement, "I should not eat high-fat foods": $M=2.8(S D=1.9)$ vs. $M=4.1(S D=1.6)$. Obese people were more convinced that they actually should not eat high-fat foods, $t(59)=2.85$, $S E M=0.44, p<.01$.

The EDE-Q total scores of the obese group $(M=1.98$, $S D=1.16)$ differed significantly from the control group $(M=0.27, S D=0.27), t(27.4)=7.29, S E M=0.23, p<.001$. The EDE-Q total scores of the obese group were a little high relative to norms reported by Fairburn and Cooper (1993). Scores of the control group were a little lower than norms reported by Cooper, Cooper, and Fairburn (1989) and Fairburn and Cooper (1993). The EDE-Q score correlated significantly with Statement 3, "I should not eat high-fat foods" $(r=-.47, p<.001)$ and 
Statement 4, "In my family, we watch our fat intake" $(r=-.32$, $p<.01)$. None of the explicit measures correlated significantly with the SDS.

\section{IAT Compared With Explicit Measures}

In the first explicit task, palatability was measured, comparing high-fat foods with low-fat foods. These palatability measures did not correlate significantly with the IAT effect $(p>.20)$. In the second explicit task, different attitudes and habits concerning high-fat foods were measured. Only Statement 3 ("I should not eat high-fat foods") correlated significantly with the IAT effect ( $r=$ $-.26, p<.05)$. EDE-Q total score correlated significantly with the IAT effect as well $(r=.24, p<.05)$. Scores on the subscales Restraint $(r=.26, p<.05)$, Weight Concern $(r=.27, p<.05)$, and Shape Concern $(r=.27, p<.05)$ correlated significantly with the IAT effect, whereas the scores on the subscale Eating Concern did not $(r=.14, p>.10)$. Finally, the number of diet attempts correlated significantly with the IAT effect $(r=.35, p<.01)$.

\section{Discussion}

The hypothesis was that obese people would show a larger preconscious, automatic, positive response when presented with high-fat food words than would normal-weight controls. The automatic positive response to high-fat foods would be an implicit expression of obese people's explicit preference for high-fat foods, which has been shown in various studies (e.g., Capaldi, 1996; Drewnowski, 1991; Drewnowski et al., 1992; Reed et al., 1997).

However, our results showed that obese people found it easier to respond with the same key to the combination of high-fat food words and negative words as compared with the reverse combination. These results suggest an implicit negative attitude toward high-fat foods. The same was true for normal-weight controls, but the effect was less pronounced; their responses suggested a smaller negative attitude toward high-fat foods. We uncovered an interaction between group and fat-valence combination. Unpackaging this interaction revealed that obese individuals were significantly slower than controls in responding to the combination of high-fat and positive words. This suggests that it was more difficult for obese people to create a positive/high-fat merged set or linkage. These implicit data correspond to the findings on explicit tests that showed that participants had rather negative views about high-fat foods and reported preferring low-fat foods to high-fat foods. This was true for obese people in particular. However, these latter results should be interpreted with caution because of possible socially desirable responses.

Why do obese participants show explicit as well as implicit negative attitudes toward high-fat foods, whereas they actually eat more high-fat foods? In de Houwer's (2001, in press) studies, he showed that IAT effects reflect attitudes toward the concept dimension and not toward the individual exemplars of this concept dimension. In the current study, it means that the IAT effect does not reflect a global attitude toward each of the food stimuli but rather an attitude specifically toward the fat content of these stimuli. In other words, the IAT in our study measured the association between the dimensions of high-fat/low-fat and positive/ negative. Obese people probably learned in their often numerous diet attempts that high-fat foods are "forbidden," even though they like the taste. It is quite possible that this intense learning even showed on an implicit task, which specifically focused on the fat content of foods. More evidence for this line of reasoning can be found in the significant correlations between the IAT effect and the number of diet attempts, the EDE-Q scores, and the explicit attitudes and habits concerning high-fat foods. Moreover, no significant correlations were found between explicit tests for taste preferences and the IAT effect.

Swanson, Swanson, and Greenwald (2001) found similar results for smokers in their study. Their findings suggest that smokers have an implicit negative attitude toward smoking; smokers preferred nonsmoking to smoking. This implicit negative attitude is contradictory to their behavior of smoking.

Note that the IAT is only one operational definition of one sort of implicit processes. The IAT assumes that attitudes are bipolar in nature and directs participants' attention toward one salient aspect of the stimuli (in this study, fat content). It is quite possible that if the implicit attitude toward high-fat foods were measured in a different paradigm that was not bipolar in nature and did not focus attention on fat content, different results would emerge (e.g., affective priming paradigm; Fazio et al., 1986).

To summarize, in this study we measured conscious (explicit) and automatic (implicit) evaluations of high-fat food items of obese and normal-weight participants. The IAT only targeted the implicit attitude toward one relevant feature (fat content) of the targets (de Houwer, 2001, in press). Results suggest that both obese and normal-weight controls have an implicit as well as an explicit negative attitude toward high-fat foods. This effect was more pronounced for obese people. To further our understanding of these results, an interesting avenue for future research would be to examine these implicit attitudes in different paradigms and contexts.

\section{References}

Capaldi, E. D. (1996). Conditioned food preferences. In E. D. Capaldi (Ed.), Why we eat what we eat: The psychology of eating (pp. 53-80). Washington, DC: American Psychological Association.

Cooper, Z., Cooper, P. J., \& Fairburn, C. G. (1989). The validity of the Eating Disorder Examination and its subscales. British Journal of Psychiatry, 154, 807-812.

Crowne, D., \& Marlow, D. (1964). The approval motive. New York: Wiley.

de Houwer, J. (2001). A structural and process analysis of the Implicit Association Test. Journal of Experimental Social Psychology, 37, 443451.

de Houwer, J. (in press). A structural analysis of indirect measures of attitudes. In J. Musch \& K. C. Klauer (Eds.), The psychology of evaluation: Affective processes in cognition and emotion. Mahwah, NJ: Erlbaum.

Drewnowski, A. (1991). Obesity and eating disorders: Cognitive aspects of food preference and food aversion. Bulletin of the Psychonomic Society, 29, 261-264.

Drewnowski, A. (1996). The behavioral phenotype in human obesity. In E. D. Capaldi (Ed.), Why we eat what we eat: The psychology of eating (pp. 291-308). Washington, DC: American Psychological Association.

Drewnowski, A., Brunzell, J. D., Sande, K., Iverius, P. H., \& Greenwood, M. R. (1985). Sweet tooth reconsidered: Taste responsiveness in human obesity. Physiology \& Behavior, 35, 617-622.

Drewnowski, A., \& Greenwood, M. R. (1983). Cream and sugar: Human preferences for high-fat foods. Physiology \& Behavior, 30, 629-633. 
Drewnowski, A., Kurth, C., Holden-Wiltse, J., \& Saari, J. (1992). Food preferences in human obesity: Carbohydrates versus fats. Appetite, 18, 207-221.

Fairburn, C. G., \& Beglin, S. J. (1994). The assessment of eating disorders: Interview or self-report questionnaire? International Journal of Eating Disorders, 16, 363-370.

Fairburn, C. G., \& Cooper, Z. (1993). The Eating Disorder Examination (12th ed.). In C.G. Fairburn \& G. T. Wilson (Eds.), Binge eating: Nature, assessment, and treatment (pp. 317-332). New York: Guilford Press.

Fazio, R. H., Sanbonmatsu, D. M., Powell, M. C., \& Kardes, F. R. (1986). On the automatic activation of attitudes. Journal of Personality and Social Psychology, 50, 229-238.

Greenwald, A. G., McGhee, D. E., \& Schwartz, J. L. K. (1998). Measuring individual differences in implicit cognition: The Implicit Association Test. Journal of Personality and Social Psychology, 74, 1464-1480.

Hasher, L., \& Zacks, R. T. (1988). Working memory, comprehension, and aging: A review and a new view. In G. H. Bower (Ed.), The psychology of learning and motivation: Advances in research and theory (Vol. 22, pp. 193-225). San Diego, CA: Academic Press.

Hermans, D., \& de Houwer, J. (1994). Affective and subjective familiarity ratings of 740 Dutch words. Psychologica Belgica, 34, 115-139.

Hermans, D., \& Eelen, P. (1997). Experimentele evidentie voor de oude hypothese [Experimental evidence for the old hypothesis]. Nederlands Tijdschrift voor de Psychologie, 52, 57-66.

Reed, D. R., Bachmanov, A. A., Beauchamp, G. K., Tordoff, M. G., \&
Price, A. R. (1997). Heritable variation in food preferences and their contribution to obesity. Behavior Genetics, 27, 373-387.

Swanson, J. E., Swanson, E., \& Greenwald, A. G. (2001). Using the Implicit Association Test to investigate attitude-behavior consistency for stigmatised behaviour. Cognition \& Emotion, 15, 207-230.

Wilson, G. T., \& Smith, D. (1989). Assessment of bulimia nervosa: An evaluation of the Eating Disorder Examination. International Journal of Eating Disorders, 8, 173-179.

\section{Appendix}

Stimuli (Translated From Dutch)

\begin{tabular}{llll}
\hline \multicolumn{1}{c}{ High-fat } & \multicolumn{1}{c}{ Low-fat } & Positive & Negative \\
\hline Potato chips & Popcorn & Love & Crime \\
French fries & Rice & Smile & Hate \\
Peanut butter & Jelly & Kiss & Torture \\
Chocolate & Licorice & Friend & War \\
Ice cream & Strawberries & Holidays & Murder \\
Sausage & Chicken & Peace & Accident \\
\hline
\end{tabular}

Received April 9, 2001

Revision received January 17, 2002

Accepted January 28, 2002 